\title{
Rapid photocatalytic degradation of phenol from water using composite nanofibers under UV
}

\author{
Alaa Mohamed ${ }^{1,2^{*}}$ (D, Samy Yousef ${ }^{3,4}$, Walaa S. Nasser ${ }^{5}$, T. A. Osman ${ }^{6}$, Alexander Knebel ${ }^{1}$, \\ Elvia P. Valadez Sánchez ${ }^{1}$ and Tawheed Hashem ${ }^{1,7^{*}}$
}

\begin{abstract}
Background: The removal of phenol from aqueous solution via photocatalytic degradation has been recognized as an environmentally friendly technique for generating clean water. The composite nanofibers containing PAN polymer, $\mathrm{CNT}$, and $\mathrm{TiO}_{2} \mathrm{NPs}$ were successfully prepared via electrospinning method. The prepared photocatalyst is characterized by SEM, XRD, and Raman spectroscopy. Different parameters are studied such as catalyst amount, the effect of $\mathrm{pH}$, phenol concentration, photodegradation mechanism, flow rate, and stability of the composite nanofiber to evaluate the highest efficiency of the photocatalyst.
\end{abstract}

Results: The composite nanofibers showed the highest photodegradation performance for the removal of phenol using UV light within $7 \mathrm{~min}$. The $\mathrm{pH}$ has a major effect on the photodegradation of phenol with its maximum performance being at $\mathrm{pH} 5$.

Conclusions: Given the stability and flexibility of the composite nanofibers, their use in a dynamic filtration is possible and can be even reused after several cycles.

Keywords: Composite nanofibers, Phenol, Photodegradation, Electrospinning, UV light

\section{Background}

The contamination of water resources is a serious environmental concern. The water quality has been constantly decreasing due to the existence of different pollutants such as dyes, synthetic hormones, phenol, and pharmaceuticals $[1,2]$. Phenol and phenolic compounds are one of the most persistent toxic organic pollutants discharged in wastewater effluents, which are resistant to environmental degradation through chemical, biological, and photolytic processes [3, 4]. The major sources of phenol and phenolic compounds are discharges of chemical process industries such as pulp and paper,

*Correspondence: alakha@kth.se; tawheed.hashem@kit.edu

${ }^{1}$ Institute of Functional Interfaces (IFG), Karlsruhe Institute of Technology (KIT), Hermann-von Helmholtz-Platz 1, 76344 Eggenstein-Leopoldshafen, Germany

Full list of author information is available at the end of the article pharmaceutical, agrochemical, petrochemical, and pesticide production [5]. The accumulation of these pollutants can have adverse effects on human health due to their toxicity, their ability to disrupt the endocrine system and their carcinogenic behavior [6]. Therefore, the improper handling and disposal of these toxic carcinogenic compounds pose a significant risk to the environment and the ecosystem $[7,8]$. In order to deal with such pollutants, conventional adsorption technologies, such as biological degradation, chemical oxidation, adsorption, and photocatalysis are used for removal procedures $[9,10]$.

In recent years, photocatalysis has become an alternative for the removal of organic pollutants, including the treatment of phenolic wastewater s due to its economic, efficient, and green feature $[11,12]$. Photocatalysis has many advantages including its use in UV, visible light radiation, and no waste because of its complete mineralization at the end of disintegration [13]. In addition, 
organic pollutants decompose in the presence of a wideband gap semiconductor which can promote reactions in the existence of UV light without being consumed in the entire reaction.

$\mathrm{TiO}_{2}$ is one of the most active catalysts among the semiconductors for the treatment of organic and contaminated components, due to its photosensitivity, low price, biological activity, and chemical stability $[14,15]$. In practical applications, it is necessary to recover the remaining $\mathrm{TiO}_{2}$ nanoparticles in the photocatalytic reaction solution. In addition, carbon nanotube $(\mathrm{CNT})$ has received a lot of attention as adsorbent due to their large specific surface area, small size, high porosity, and light mass density $[16,17]$. The combining of $\mathrm{TiO}_{2}$ with $\mathrm{CNTs}$ has shown a major effect that can improve the overall performance of the photocatalytic process $[15,18]$. $\mathrm{TiO}_{2}$ is actually an n-type semiconductor, however, in the existence of CNTs, photogenerated electrons can move freely towards to the surface of CNTs surface, which may have a lower Fermi level and leave too much valence band holes in the $\mathrm{TiO}_{2}$ to migrate to the surface and react $[19,20]$. Also, CNTs can provide $\mathrm{TiO}_{2}$ with space restriction and a larger contact area, which leads to faster observed redox reaction rate [21]. Further, the application of anodic potentials to irradiated $\mathrm{TiO}_{2} / \mathrm{CNTs}$ composite can be further improved [22, 23]. The uniformity of the oxide coating and the physical properties of the composite materials vary depending on the manufacturing processes. In this regard, composite nanofibers have been used to immobilize $\mathrm{TiO}_{2} / \mathrm{CNTs}$ on the nanofibers $[24,25]$.

The hybrid photocatalysis and nanofiber membrane combines the advantages of both, membrane filtration and photocatalytic degradation. This approach allows the possibility of creating composite nanofibers membranes with superior removal efficiency and selectivity that lead to the development of a new water treatment solution [26, 27]. Given its facility of control and environmental sustainability, electrospinning is a versatile and effective process for the production of composite nanofibers with diameters from nanometers to submicrometers and characterized by their low cost, ease of use, and unique properties [28]. Electrospun PAN can be a promising carrier for immobilized catalytic materials since electrospun nanofibers based on PAN are hydrophobic, have a low density and are flexible in operation, thereby ensure easy floating on liquid or fixing at the desired location in the reactors $[29,30]$. The above considerations form the basis of our further work. Herein, we investigate the utilization of a PAN-CNT/ $\mathrm{TiO}_{2}-\mathrm{NH}_{2}$ nanofiber membrane in the application of organic wastewater decontamination. In this paper, the properties of PAN-CNT/TiO $-\mathrm{NH}_{2}$ composite nanofibers by SEM, XRD, Raman spectra, and
UV-Vis were investigated. The effect of catalyst dosage, contact time, $\mathrm{pH}$ solution, photodegradation mechanism, flow rate, and phenol concentration on the photocatalytic degradation of phenol under UV light are presented.

\section{Materials and methods \\ Chemicals and materials}

Analytical-grade chemicals used in this work were purchased from Sigma-Aldrich Sweden Ltd. PAN $(\mathrm{MW}=150,000)$, Aeroxide $\mathrm{TiO}_{2}, 3$-aminopropyltriethoxysilane, glutaraldehyde, polyacrylonitrile, dimethylformamide (DMF), sodium hydroxide and hydrochloric acid were used in the experimental studies. The variation of $\mathrm{pH}$ in the feed solutions was maintained by adding $0.1 \mathrm{M}$ $\mathrm{HCl}$ and $0.1 \mathrm{M} \mathrm{NaOH}$. MWCNTs were synthesized following the procedure described in Yousef et.al [31]. Phenol (99.0\%) was used to make standards and aqueous solutions for photocatalytic reactions.

\section{Material preparation}

10 wt. \% of PAN was dissolved in DMF and stirred for $5 \mathrm{~h}$. The, 1 wt. $\%$ of CNT was added to the PAN/DMF solution. The mixed solution was stirred for an additional $24 \mathrm{~h}$ and used for nanofiber preparation. For electrospun nanofibers, $1 \mathrm{~mL} / \mathrm{h}$ flow rate and $25 \mathrm{kV}$ was required. The modified surfaces of $\mathrm{TiO}_{2}$ NPs were described in our previous work. A mixture of $0.5 \mathrm{~g}$ of $\mathrm{TiO}_{2}$ and $10 \mathrm{~mL}$ deionized water were mixed to facilitate the adsorption of the hydroxyl group. The $\mathrm{TiO}_{2}$ were dispersed in $100 \mathrm{ml}$ of toluene via ultrasonication for $30 \mathrm{~min}$. Then $3 \mathrm{ml}$ of the silane was added to the solution. The suspension was refluxed at $110{ }^{\circ} \mathrm{C}$ for $24 \mathrm{~h}$ creating $\mathrm{NH}_{2}$ functional groups on the titanium dioxide. The nanofibers were then immersed in a crosslinking medium composed of $100 \mathrm{~mL}$ distilled water and $2.5 \mathrm{wt} \% \mathrm{GA}$ and then shaken for $24 \mathrm{~h}$.

\section{Material characterization}

The surface morphology of the composite nanofibers were characterized by field emission scanning electron microscope (FE-SEM, S-5000, Hitachi, Japan) using an acceleration voltage of $10 \mathrm{kV}$. The crystal structure of the samples was determined via X-ray diffraction (XRD) patterns, which was recorded with a Bruker D8-Advance using $\mathrm{Cu}-\mathrm{Ka}$ radiation at a step time of $0.2 \mathrm{~s}$ per point in the range of $20-80^{\circ}$. Raman spectra (Thermo scientific, DXR) were recorded between 0 and $2000 \mathrm{~cm}^{-1}$ with $514 \mathrm{~nm}$ wavelength. The UV-Vis absorption spectrum of the phenol samples were recorded after irradiation in a wavelength range of $200-500 \mathrm{~nm}$ with a UV-visible spectrophotometer (Lambda 35, PerkinElmer). 


\section{Photocatalysis experiments}

The photocatalytic degradation experiments of phenol were carried out under dynamic conditions of a flow rate of $7 \mathrm{ml} / \mathrm{min}$ using ultraviolet (UV) radiation as shown in Fig. 1 . The photoreactor is a cylindrical pyrex-glass column with a capacity of $250 \mathrm{ml}$, an inner diameter of $20 \mathrm{~mm}$, and a height of $300 \mathrm{~mm}$. A UV-A lamp (315-400 nm) was used as a UV light source with an intensity of $100 \mathrm{~W}$. The nanofiber mat $(3 \times 6 \mathrm{~cm}, 50 \mathrm{mg})$ was immersed in the phenol solution with the concentration of $10 \mathrm{mg} / \mathrm{L}$ before each experiment. The suspension was kept in the dark for $30 \mathrm{~min}$ to achieve the equilibrium on the surfaces of the composite nanofibers. After that, the sample was exposed to UV light; reference samples were collected for analysis. At a given interval time, $3 \mathrm{~mL}$ suspension was collected and analyzed using a UV-visible spectrophotometer. All experiments were duplicated to assure the consistency and reproducibility of the results. The effect of initial phenol concentration (10-100 mg/L) and $\mathrm{pH}$ values from (2-9) were examined. The photodegradation efficiency of phenol can be expressed as follows:

$$
\text { Photodegradationefficiency }(\%)=\frac{C_{i}-C_{o}}{C_{i}} \bullet 100,
$$

where $C_{i}$ and $C_{0}(\mathrm{mg} / \mathrm{L})$ are the initial and equilibrium concentration of phenol. The filtration performance of the composite nanofiber membranes was also characterized. After pre-wetting the nanofibers mat with DI water for $1 \mathrm{~h}$, the membrane was fixed in the photoreactor. The pure water flux was calculated at various flow rates as follows:

$$
\text { Purewaterflux }(J 0)=\frac{m_{\mathrm{p}}}{\mathrm{t} \bullet \rho_{\mathrm{w}} \bullet \mathrm{A}_{\mathrm{m}}},
$$

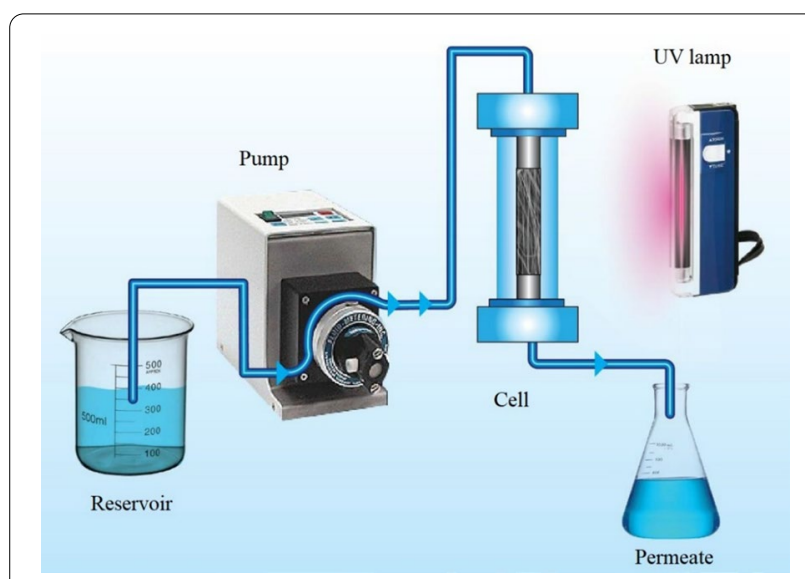

Fig. 1 Schematic diagram of photoreactor system where $m_{P}$ is the mass of permeate $(\mathrm{g}), \mathrm{t}$ is the filtration time, $A_{m}$ is the area of the composite membrane $\left(\mathrm{cm}^{2}\right)$, and $\rho_{\mathrm{w}}$ is the density of water $\left(\mathrm{g} / \mathrm{cm}^{3}\right)$.

\section{Results and discussion}

To confirm the successful crosslinking process, preparation, and immobilization of NPs loaded on the nanofiber, SEM, XRD, and Raman spectra were carried out. Figure $2 \mathrm{a}$ and $\mathrm{b}$ shows the surface morphologies of the PAN$\mathrm{CNT}$ and $\mathrm{PAN}-\mathrm{CNT} / \mathrm{TiO}_{2}-\mathrm{NH}_{2}$ composite nanofibers. It was clearly observed that the composite nanofiber membrane was smooth and uniform and crosslinked well with the NPs on the top surface of the nanofiber. The XRD analysis of PAN-CNT/TiO $2-\mathrm{NH}_{2}$ composite nanofiber is presented in Fig. 2c, proving the highly crystalline character of the $\mathrm{TiO}_{2}$ and CNTs nanoparticles. In addition, Fig. 2d shows the Raman spectra of the PAN, CNT, $\mathrm{TiO}_{2}$, and $\mathrm{PAN}-\mathrm{CNT} / \mathrm{TiO}_{2}-\mathrm{NH}_{2}$ composite nanofibers. The result shows that the composite nanofibers contain all the characteristic peaks of PAN, CNT, and $\mathrm{TiO}_{2}$, confirming the successful fabrication of the composite nanofiber membrane $[32,33]$.

\section{Photocatalytic performance of composites nanofibers}

To maximize the degradation efficiency, catalyst dose was found to be the potential catalyst for the degradation of phenol [34]. In order to explore its effective concentration, reactions were carried out with different catalyst quantities $\left(\mathrm{TiO}_{2}-\mathrm{NH}_{2)}\right.$ ranging from 5 to $30 \mathrm{mg}$ and the amount of CNT fixed at $3 \mathrm{mg}$ at $10 \mathrm{mg} / \mathrm{L}$ concentrations of phenol. At higher $\mathrm{TiO}_{2}-\mathrm{NH}_{2}$ the catalytic performance of the composite nanofibers is much better for the same photocatalytic time as shown in Fig. 3 . The $20 \mathrm{mg}$ catalyst showed the best photodegradation efficiency in $7 \mathrm{~min}$. This behavior is due to the increase in the number of active sites and the high surface area of the nanofiber [35]. Therefore, the increase in electron-hole pairs on the catalyst surface leads to higher amounts of reactive hydroxyl radicals, which can be attributed to better degradation. The increased loading with $\mathrm{CNT} / \mathrm{TiO}_{2}-\mathrm{NH}_{2}$ provides more binding sites for substrate molecules to adsorb on the catalyst surface [36].

Furthermore, the $\mathrm{pH}$ of the system exerts a profound influence on adsorption and absorption due to its influence on the surface properties of the adsorbent and ionization/dissociation of the ion [37]. In this study, the $\mathrm{pH}$ value range between 2 and 9 was explored, as shown in Fig. 4. Apparently, after 7 min of UV irradiation, the degradation efficiency at $\mathrm{pH} 5$ is about $99.2 \%$ and drops to $85 \%$ at $\mathrm{pH}$ 9. The photodegradation efficiency at $\mathrm{pH} 2$ is slightly lower than at $\mathrm{pH} 6$, which is due to the potential dissociation of $\mathrm{PAN}-\mathrm{CNT} / \mathrm{TiO}_{2}-\mathrm{NH}_{2}$ composite nanofiber and the $\mathrm{Cl}^{-}$ions that generated through $\mathrm{pH}$ 

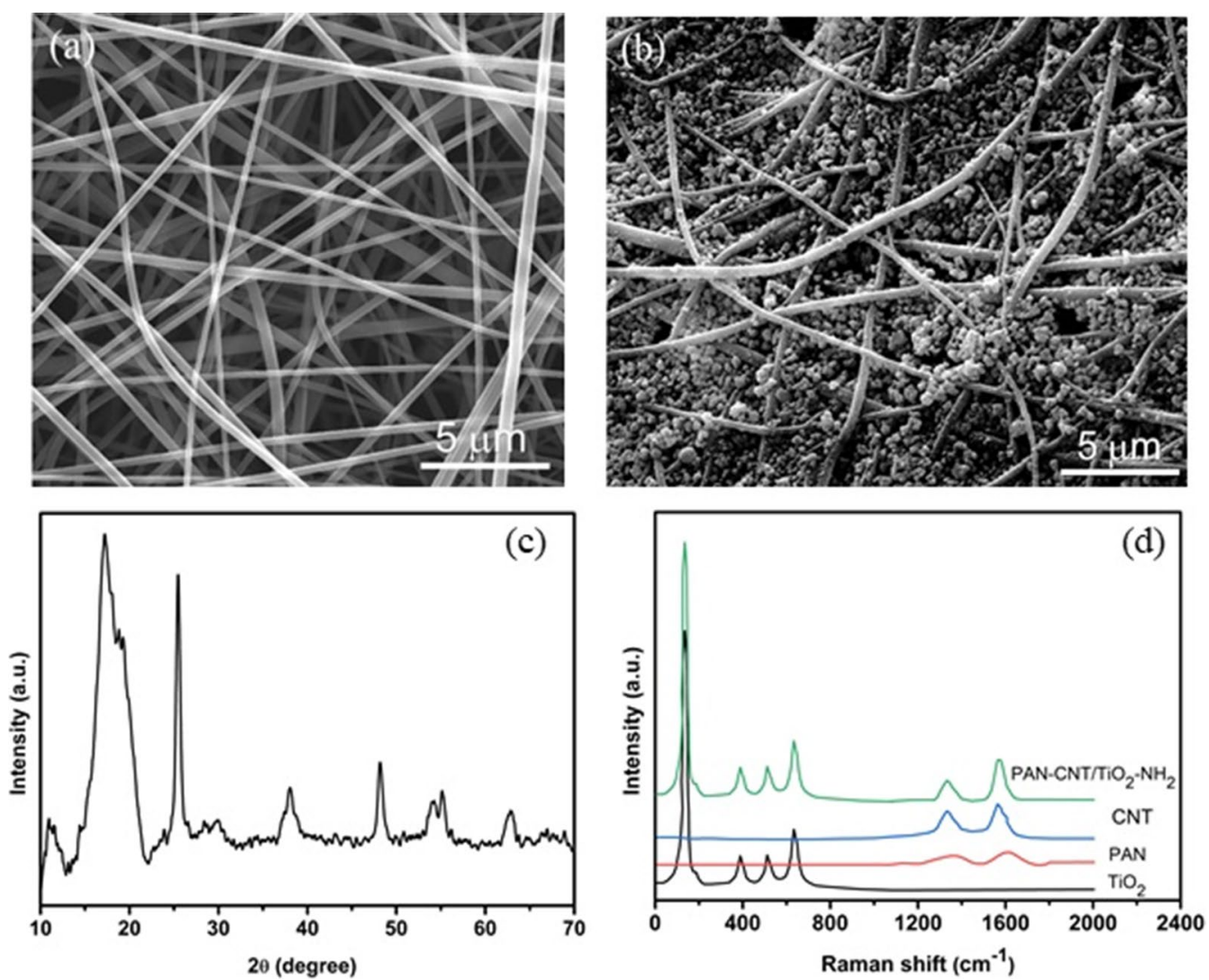

Fig. 2 a SEM image of PAN-CNT nanofiber, b PAN-CNT/TiO $\mathrm{O}_{2}-\mathrm{NH}_{2}$ composite nanofiber, $\mathbf{c}$ XRD analysis, and $\mathbf{d}$ Raman spectra of the PAN-CNT/ $\mathrm{TiO}_{2}-\mathrm{NH}_{2}$ composite nanofibers
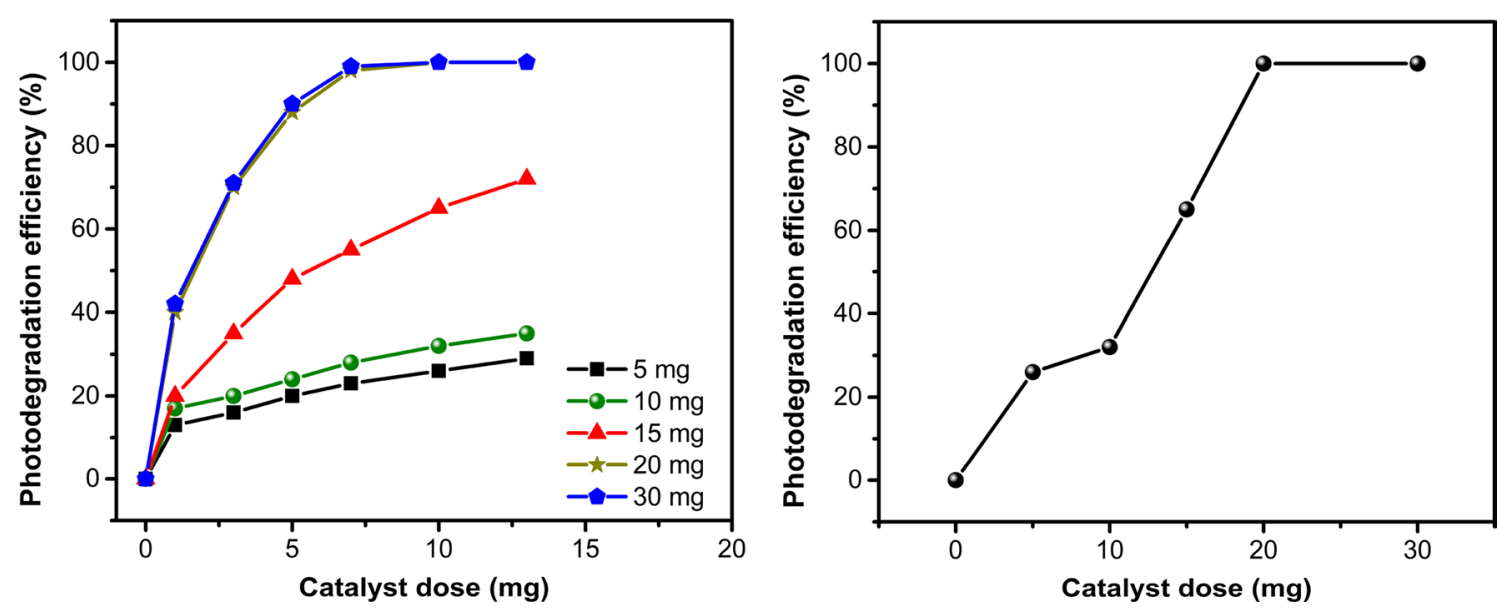

Fig. 3 Effect of catalyst amount on the photodegradation of phenol (10 mg/L phenol, time $7 \mathrm{~min}$, and $\mathrm{pH}$ 7)

adjustment compete with phenol for adsorption, thereby reducing adsorption and photocatalytic performance under strongly acidic conditions [38]; whereas, at high alkaline, the photodegradation performance is highly lower. The variation in the photodegradation efficiency with $\mathrm{pH}$ can be attributed to the strong electrostatic interaction between phenol and $\mathrm{TiO}_{2}$ at a neutral state [39].

The suitable condition for the maximum degradation of $10 \mathrm{mg} / \mathrm{L}$ phenol was finalized by optimizing various 

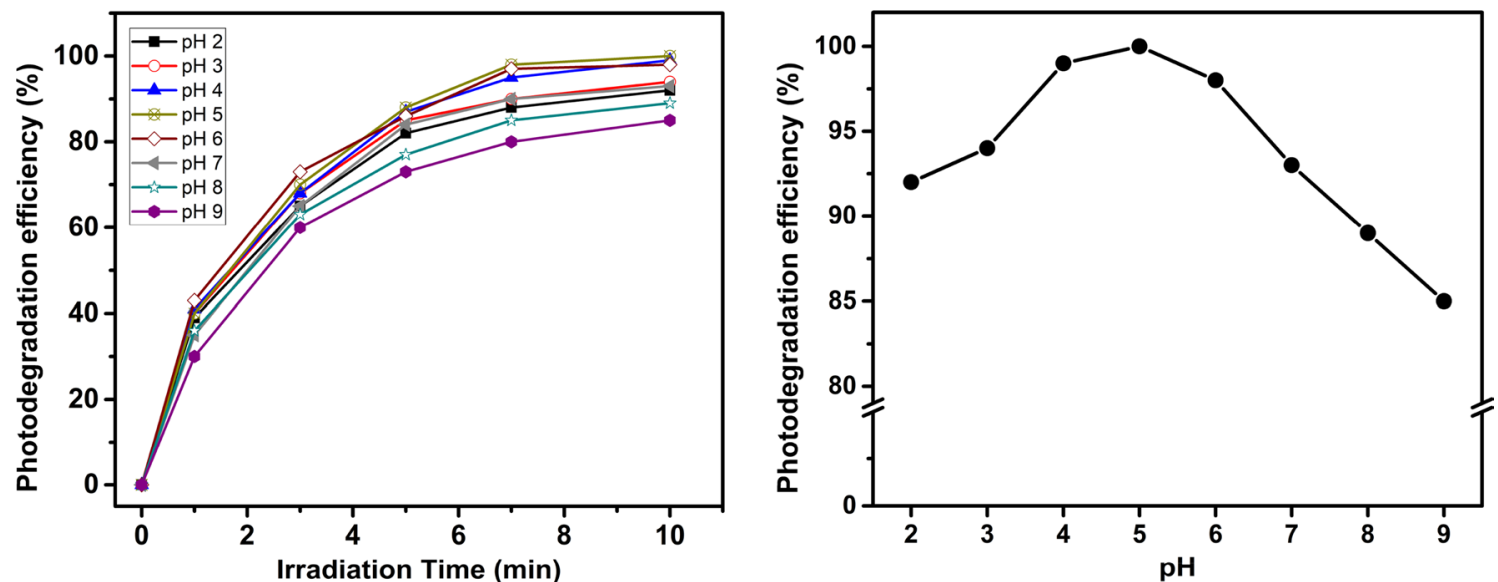

Fig. 4 Effect of $\mathrm{pH}$ on the photodegradation of phenol (10 mg/L phenol)
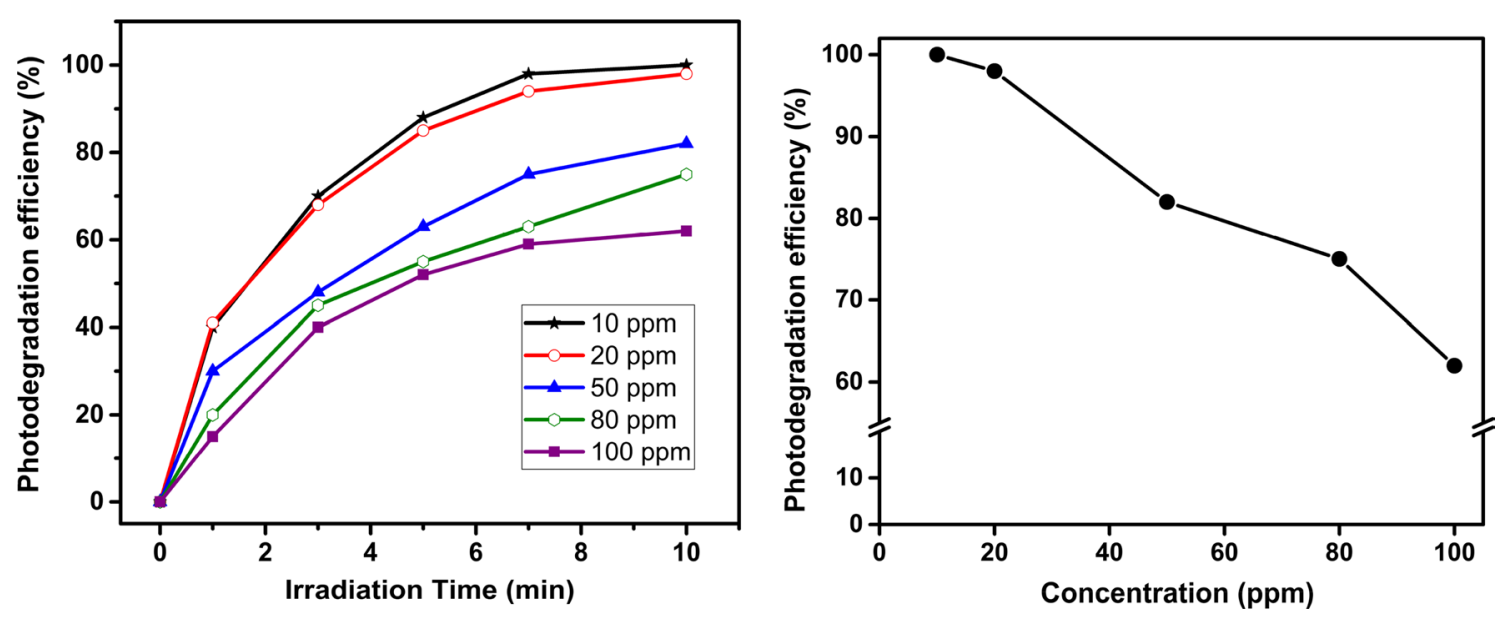

Fig. 5 Effect of phenol concentration on the photodegradation of phenol

reaction parameters. The effect of phenol concentration on degradation efficiency was performed by increasing the concentration from $10 \mathrm{mg} / \mathrm{L}$ to $100 \mathrm{mg} / \mathrm{L}$ (Fig. 5). The result shows that at $\mathrm{pH} 5$ the photodegradation efficiency decreased with increasing phenol concentration from 10 to $100 \mathrm{mg} / \mathrm{L}$. The photodegradation efficiency at $100 \mathrm{mg} / \mathrm{L}$ was $60 \%$ in less than $10 \mathrm{~min}$. This behavior may be attributed to the fact that due to the increased phenol concentration, the energy of the UV light is intercepted before reacting with the photocatalyst.

Figure 6 shows the individual components of the composite nanofiber to evaluate the photodegradation mechanism of phenol. The photocatalytic degradation efficiency of $\mathrm{PAN} / \mathrm{TiO}_{2}-\mathrm{NH}_{2}$ and PAN-CNT was 79 and $45 \%$, respectively. These results indicate that the photodegradation performance of phenol over the PAN$\mathrm{CNT} / \mathrm{TiO}_{2}-\mathrm{NH}_{2}$ composite nanofiber is more than $\mathrm{PAN} / \mathrm{TiO}_{2}-\mathrm{NH}_{2}$ which can be attributed to that CNTs

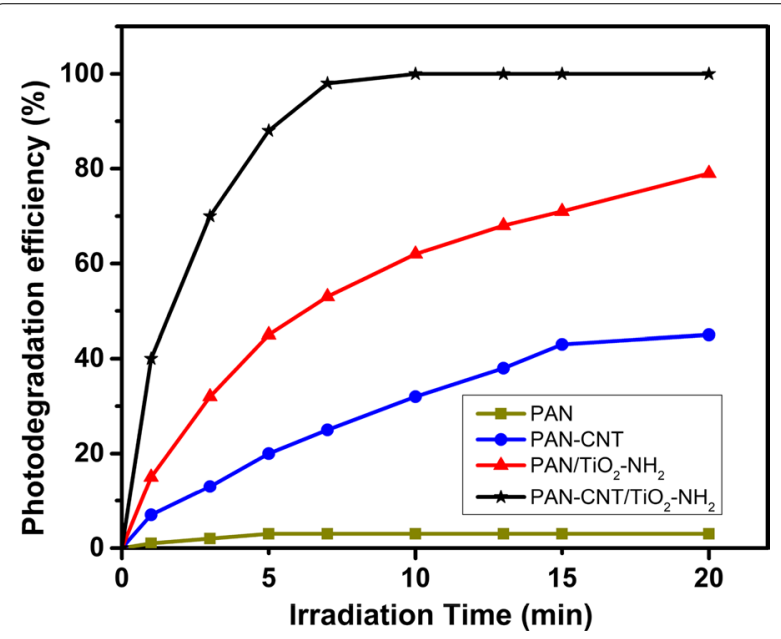

Fig. 6 Effect material components on the photodegradation of phenol (10 mg/L, pH 5) 


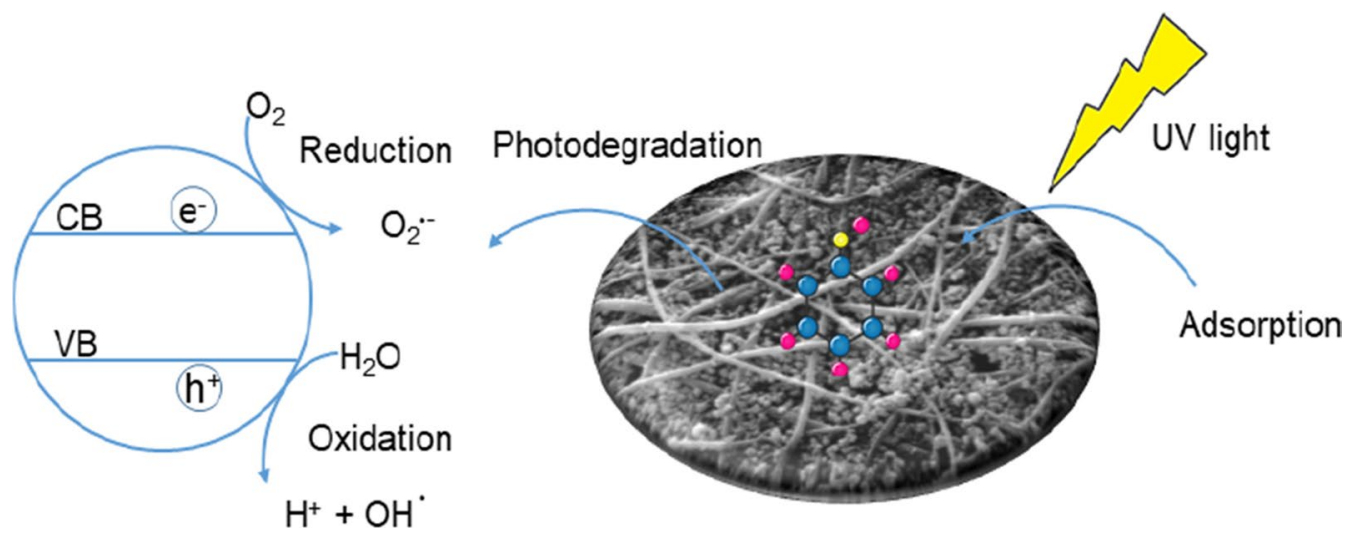

Fig. 7 Mechanism of phenol degradation on the composite nanofiber membrane

play an important role in improving the photodegradation efficiency and the increasing the number of active sites and the adsorption strength of each active site. The photodegradation mechanism of phenol using the composite nanofiber depends on the active species $\mathrm{OH}$ which is the key to the degradation process of organic substrates. To initiate the photoreaction, $\mathrm{TiO}_{2}$ is irradiated with energy equal or higher than its band gap. The photogenerated electrons are raised to the conduction band $(\mathrm{CB})$ and photogenerated holes remain in the valence band (VB) [45]. The positively charged electron hole $(\mathrm{h}+)$ reacts with water to form $(\cdot \mathrm{OH})$ as shown in Fig. 7. Meanwhile the excited electron reduces an oxygen molecule to $\left(\mathrm{O}_{2}{ }^{\cdot-}\right)$ for degrading phenol to small molecules [46]. In addition, several researchers proposed that photocatalyst attack the hydroxyl radicals on the phenyl ring, resulting in the formation of catechol, then further oxidizing to oxalic acid and mineralizing to $\mathrm{CO}_{2}$ and $\mathrm{H}_{2} \mathrm{O}$.

The reusability and stability performance of photocatalytic composite nanofibers is highly attractive for practical applications. Therefore, the photocatalytic degradation was performed for 3 cycles of photodegradation at $10 \mathrm{mg} / \mathrm{L}$ and $\mathrm{pH} 5$ for $15 \mathrm{~min}$ under UV irradiation. Figure 8 shows its reusability and stability performance. The result showed that no significant decrease could be observed in the catalytic performance of the composite nanofiber membrane after three recycle experiments. This reveals that the catalyst is stable for more than 3 cycles and can be easily recycled for further use, which gives it a great potential in practical water treatment.

The pure water flux of the composite nanofiber membrane was tested as a function of the flow rate as shown in Fig. 9. The results show that the flux increases linearly with the flow rate. In general, the high flux of the
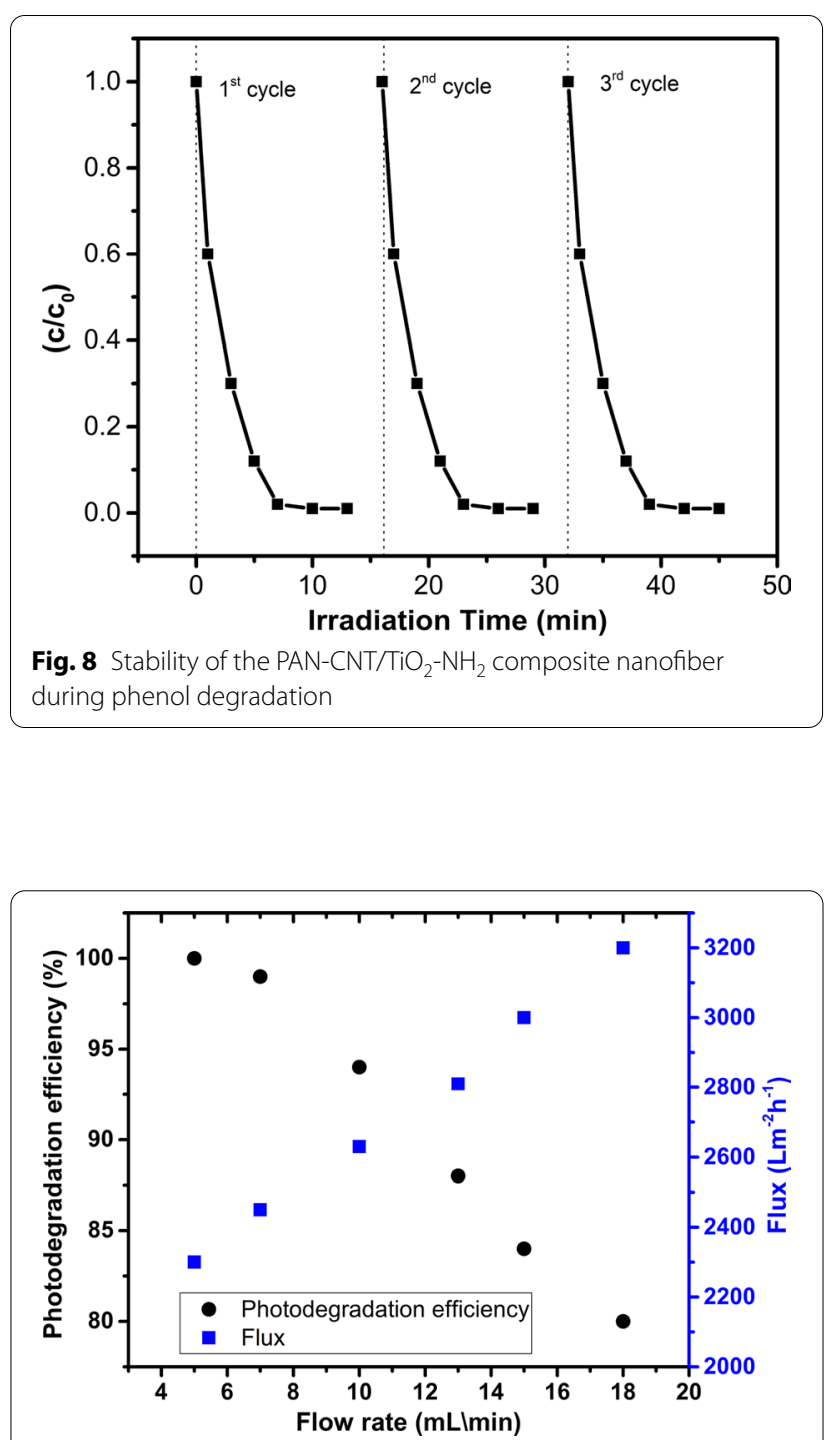

Fig. 9 Photodegradation efficiency and flux as a function of flow rate using the PAN-CNT/TiO ${ }_{2}-\mathrm{NH}_{2}$ composite nanofiber membrane 
composite nanofiber membrane is strongly desired as it consumes less energy and has high throughput which are the most important advantages pursued.

\section{Conclusions}

In summary, PAN-CNT/ $\mathrm{TiO}_{2}-\mathrm{NH}_{2}$ composite nanofibers were successfully prepared via electrospinning processes for photocatalytic degradation of phenol by UV light. The composite nanofibers have stable performance and high photodegradation for phenol under UV light; nearly $99 \%$ within $7 \mathrm{~min}$. This is attributed to the large surface area of the composite nanofiber which leads to significant improvement in light absorption, thereby achieving accelerated photodegradation and improving the photodegradation efficiency. The best result was achieved at the optimal condition of $20 \mathrm{mg}$ catalyst, $10 \mathrm{mg} / \mathrm{L}$ phenol in neutral $\mathrm{pH}$ which is 5 , and $7 \mathrm{~min}$. In addition, the composite nanofibers are stable and reusable more than three times, which is an attractive performance for practical applications. Therefore, the present photocatalytic composite nanofiber membrane is an attractive option for large-scale environmental purification. Furthermore, compared to conventional nano-sized powder photocatalytic materials, it can be easily separated from the filtration system after photocatalytic reaction and reused more easily.

\section{Abbreviations}

$\mathrm{TiO}_{2}$ : Titanium dioxide; CNT: Carbon nanotube; PAN: Polyacrylonitrile.

\section{Acknowledgement}

T. Hashem acknowledges support through the Cluster "3DMM2O"funded by the Deutsche Forschungsgemeinschaft (DFG, German Research Foundation) under Germany`s Excellence Strategy - 2082/1 - 390761711.

\section{Authors' contributions}

AM: conceptualization, methodology, investigation, writing —original draft, writing —review and editing. SY: review and editing. WN: writing —original draft, analysis. TO, AK, EV, TH: review and editing. All authors read and approved the final manuscript.

\section{Funding}

Open Access funding enabled and organized by Projekt DEAL. Cluster "3DMM2O" funded by the Deutsche Forschungsgemeinschaft (DFG, German Research Foundation) under Germany`s Excellence Strategy - 2082/1 $-390761711$.

\section{Availability of data and materials}

Not applicable.

\section{Ethics approval and consent to participate}

Not applicable.

\section{Consent for publication}

Not applicable.

\section{Competing interests}

The authors declare that they have no competing interests.

\section{Author details}

${ }^{1}$ Institute of Functional Interfaces (IFG), Karlsruhe Institute of Technology (KIT), Hermann-von Helmholtz-Platz 1, 76344 Eggenstein-Leopoldshafen, Germany. ${ }^{2}$ Department of Mechatronics, Fifth Settlement, Canadian International College, New Cairo, Egypt. ${ }^{3}$ Department of Production Engineering, Faculty of Mechanical Engineering and Design, Kaunas University of Technology, 51424 Kaunas, Lithuania. ${ }^{4}$ Department of Materials Science, Physical and Chemical Properties of Materials, South Ural State University (National Research University), Lenin Prospect 76, 454080 Chelyabinsk, Russia. ${ }^{5}$ Research Institute of Medical Entomology, Giza 12611, Egypt. ${ }^{6}$ Mechanical Design and Production Engineering Department, Cairo University, Giza 12613, Egypt. ${ }^{7}$ Institute of Physics and Technology, International X-Ray Optics Lab, National Research Tomsk Polytechnic University (TPU), 30 Lenin ave, Tomsk 634050, Russia.

Received: 26 September 2020 Accepted: 27 November 2020 Published online: 23 December 2020

References

1. Hashem T, Ibrahim AH, Wöll C, Alkordi MH (2019) Grafting zirconiumbased metal-organic framework UiO-66-NH2 nanoparticles on cellulose fibers for the removal of $\mathrm{Cr}(\mathrm{VI})$ ions and methyl orange from water. ACS Appl Nano Mater 2:5804-5808

2. A. Mohamed, Chapter Eight - Synthesis, Characterization, and Applications Carbon Nanofibers, in: S. Yaragalla, R. Mishra, S. Thomas, N. Kalarikkal, H.J. Maria (Eds.) Carbon-Based Nanofillers and Their Rubber Nanocomposites, Elsevier, 2019, pp. 243-257.

3. Grabowska E, Reszczyńska J, Zaleska A (2012) RETRACTED: Mechanism of phenol photodegradation in the presence of pure and modified- $\mathrm{TiO}_{2}$ : a review. Water Res 46:5453-5471

4. Mohamed A, Nasser WS, Kamel BM, Hashem T (2019) Photodegradation of phenol using composite nanofibers under visible light irradiation. Eur Polymer J 113:192-196

5. Malato S, Fernández-Ibáñez P, Maldonado MI, Blanco J, Gernjak W (2009) Decontamination and disinfection of water by solar photocatalysis: recent overview and trends. Catal Today 147:1-59

6. Aboamera NM, Mohamed A, Salama A, Osman TA, Khattab A (2017) Characterization and mechanical properties of electrospun cellulose acetate/ graphene oxide composite nanofibers. Mech Adv Mater Struct 1:1-5

7. Swan SH (2008) Environmental phthalate exposure in relation to reproductive outcomes and other health endpoints in humans. Environ Res 108:177-184

8. Yazdi MG, Ivanic M, Mohamed A, Uheida A (2018) Surface modified composite nanofibers for the removal of indigo carmine dye from polluted water. RSC Adv 8:24588-24598

9. Mohamed A, Osman TA, Toprak MS, Muhammed M, Uheida A (2017) Surface functionalized composite nanofibers for efficient removal of arsenic from aqueous solutions. Chemosphere 180:108-116

10. Mohamed A, Ghobara MM, Abdelmaksoud MK, Mohamed GG (2019) A novel and highly efficient photocatalytic degradation of malachite green dye via surface modified polyacrylonitrile nanofibers/biogenic silica composite nanofibers. Sep Purif Technol 210:935-942

11. Sajjad S, Leghari SA, Chen F, Zhang J (2010) Bismuth-doped ordered mesoporous TiO2: visible-light catalyst for simultaneous degradation of phenol and chromium. Chemistry (Weinheim an der Bergstrasse, Germany) 16:13795-13804

12. Khalil A, Aboamera NM, Nasser WS, Mahmoud WH, Mohamed GG (2019) Photodegradation of organic dyes by PAN/SiO2-TiO2-NH2 nanofiber membrane under visible light. Sep Purif Technol 224:509-514

13. Mohamed A, Salama A, Nasser WS, Uheida A (2018) Photodegradation of Ibuprofen, Cetirizine, and Naproxen by PAN-MWCNT/TiO2-NH2 nanofiber membrane under UV light irradiation. Environ Sci Europe 30:47

14. Uheida A, Mohamed A, Belaqziz M, Nasser WS (2019) Photocatalytic degradation of Ibuprofen, Naproxen, and Cetirizine using PAN-MWCNT nanofibers crosslinked TiO2-NH2 nanoparticles under visible light irradiation. Sep Purif Technol 212:110-118 
15. Mohamed A, Osman TA, Toprak MS, Muhammed M, Yilmaz E, Uheida A (2016) Visible light photocatalytic reduction of $\mathrm{Cr}(\mathrm{VI})$ by surface modified CNT/titanium dioxide composites nanofibers. J Mol Catal A Chem 424:45-53

16. Mohamed A, Yousef $S$, Abdelnaby MA, Osman TA, Hamawandi B, Toprak MS, Muhammed M, Uheida A (2017) Photocatalytic degradation of organic dyes and enhanced mechanical properties of PAN/CNTs composite nanofibers. Separ Purif Technol. 182:219-223

17. Mohamed A, Osman TA, Khattab A, Zaki M (2014) Tribological behavior of carbon nanotubes as an additive on lithium grease. J Tribol 137:011801-011801

18. Salama A, Mohamed A, Aboamera NM, Osman T, Khattab A (2018) Characterization and mechanical properties of cellulose acetate/carbon nanotube composite nanofibers. Adv Polym Technol 37:2446-2451

19. Nam Y, Lim JH, Ko KC, Lee JY (2019) Photocatalytic activity of TiO2 nanoparticles: a theoretical aspect. J Mater Chem A 7:13833-13859

20. Leary R, Westwood A (2011) Carbonaceous nanomaterials for the enhancement of TiO2 photocatalysis. Carbon 49:741-772

21. Nguyen KC, Ngoc MP, Nguyen MV (2016) Enhanced photocatalytic activity of nanohybrids TiO2/CNTs materials. Mater Lett 165:247-251

22. Azzam EMS, Fathy NA, El-Khouly SM, Sami RM (2019) Enhancement the photocatalytic degradation of methylene blue dye using fabricated CNTs/TiO2/AgNPs/Surfactant nanocomposites. J Water Process Eng 28:311-321

23. Zhang W, Li G, Liu H, Chen J, Ma S, An T (2019) Micro/nano-bubble assisted synthesis of Au/TiO2@CNTs composite photocatalyst for photocatalytic degradation of gaseous styrene and its enhanced catalytic mechanism. Environ Sci Nano 6:948-958

24. Salama A, Mohamed A, Aboamera NM, Osman TA, Khattab A (2018) Photocatalytic degradation of organic dyes using composite nanofibers under UV irradiation. Appl Nanosci 8:155-161

25. Mohamed A, Nasser WS, Osman TA, Toprak MS, Muhammed M, Uheida A (2017) Removal of chromium (VI) from aqueous solutions using surface modified composite nanofibers. J Colloid Interface Sci 505:682-691

26. Abdel-Mottaleb MM, Mohamed A, Karim SA, Osman TA, Khattab A (2018) Preparation, characterization, and mechanical properties of polyacrylonitrile (PAN)/graphene oxide (GO) nanofibers. Mech Adv Mater Struct 1:1-6

27. Karim SA, Mohamed A, Abdel-Mottaleb MM, Osman TA, Khattab A (2019) Visible light photocatalytic activity of PAN-CNTs/ZnO-NH2 electrospun nanofibers. J Alloy Compd 772:650-655

28. Abdel-Mottaleb MM, Khalil A, Karim S, Osman TA, Khattab A (2019) High performance of PAN/GO-ZnO composite nanofibers for photocatalytic degradation under visible irradiation. J Mech Behav Biomed Mater 96:118-124

29. Abdel-Mottaleb MM, Khalil A, Osman TA, Khattab A (2019) Removal of hexavalent chromium by electrospun PAN/GO decorated ZnO.J Mech Behav Biomed Mater 98:205-212

30. Karim SA, Mohamed A, Abdel-Mottaleb MM, Osman TA, Khattab A (2018) Mechanical properties and the characterization of polyacrylonitrile/carbon nanotube composite nanofiber. Arabian J Sci Eng 43:4697-4702

31. Yousef S, Mohamed A (2016) Mass production of CNTs using CVD multiquartz tubes. J Mech Sci Technol 30:5135-5141

32. Wang B, Xin H, Li X, Cheng J, Yang G, Nie F (2014) Mesoporous CNT@ TiO2-C nanocable with extremely durable high rate capability for lithiumion battery anodes. Sci Rep 4:3729

33. Khalil A, Nasser WS, Osman TA, Toprak MS, Muhammed M, Uheida A (2019) Surface modified of polyacrylonitrile nanofibers by TiO2/MWCNT for photodegradation of organic dyes and pharmaceutical drugs under visible light irradiation. Environ Res 179:108788

34. Saud PS, Pant B, Alam A-M, Ghouri ZK, Park M, Kim H-Y (2015) Carbon quantum dots anchored TiO2 nanofibers: Effective photocatalyst for waste water treatment. Ceram Int 41:11953-11959

35. Khalil AM, Schäfer Al (2021) Cross-linked $\beta$-cyclodextrin nanofiber composite membrane for steroid hormone micropollutant removal from water. J Membr Sci 618:118228

36. Ameta R, Solanki MS, Benjamin S, Ameta SC (2018) Chapter 6 - Photocatalysis. In: Ameta SC, Ameta R (eds) Advanced Oxidation Processes for Waste Water Treatment. Academic Press, New York, pp 135-175

37. Aboamera NM, Mohamed A, Salama A, Osman TA, Khattab A (2018) An effective removal of organic dyes using surface functionalized cellulose acetate/graphene oxide composite nanofibers. Cellulose 25:4155-4166

38. Najam-Khan M, Dutta J (2015) Comparison of photocatalytic activity of zinc stannate particles and zinc stannate/zinc oxide composites for the removal of phenol from water, and a study on the effect of $\mathrm{pH}$ on photocatalytic efficiency. Mater Sci Semicond Process. 36:124-133

39. Mohamed A, El-Sayed R, Osman TA, Toprak MS, Muhammed M, Uheida A (2016) Composite nanofibers for highly efficient photocatalytic degradation of organic dyes from contaminated water. Environ Res 145:18-25

\section{Publisher's Note}

Springer Nature remains neutral with regard to jurisdictional claims in published maps and institutional affiliations.

\section{Submit your manuscript to a SpringerOpen ${ }^{\circ}$ journal and benefit from:}

- Convenient online submission

- Rigorous peer review

- Open access: articles freely available online

- High visibility within the field

- Retaining the copyright to your article

Submit your next manuscript at $\boldsymbol{\nabla}$ springeropen.com 